Disclosure of Interests: Karmela Kim Chan Grant/research support from: Roche: sponsored research agreement on stromal cells, Consultant for: GSK: consultant. (I am part of their immunology network, a group of about 8 immunologists who advise them regularly and broadly in the areas of inflammation and infection)., Gregory Vitone: None declared, Sara Shanaj: None declared, Aidan Tirpack: None declared, Jackie Finik: None declared, Laura Donlin: None declared, Deepak Rao Grant/research support from: Merck - Sponsored research project funding support, Consultant for: Janssen - Consultant

Scipher Medicine - Consultant

Amgen - Scientific advisory board

Patent submitted on Tph cells, Caroline Benson: None declared, Vivian Bykerk Grant/research support from: Mallinckrodt, BMS, Crescendo Biosciences, Sanofi/Regeneron., Consultant for: Amgen, Pfizer, UCB, Scipher, Sanofi/Genzyme/Regeneron, Dana Orange Consultant for: Astra Zeneca and Pfizer., Michael Brenner Grant/research support from: Roche: sponsored research agreement on stromal cells (but has nothing to do with checkpoint related disease), Consultant for: GSK: consultant. (I am part of their immunology network, a group of about 8 immunologists who advise them regularly and broadly in the areas of inflammation and infection)., Susan Goodman Grant/research support from: Novartis: research support, Consultant for: Novartis, UCB, Pfizer: consulting, Anne Bass: None declared

DOI: 10.1136/annrheumdis-2019-eular.1198

\section{AB1080 1 TOCILIZUMAB FOR REFRACTORY DYSTHYROÏD MYOPATHY (RDM) : A MONOCENTER OBSERVATIONAL STUDY OF 8 PATIENTS}

Philip Bielefeld ${ }^{1}$, Florian Baudin ${ }^{2}$, Julie Blanc ${ }^{2}$, Alain Bron ${ }^{2}$, Suzanne MouriesMartin ${ }^{1}$, Romain Bouvet ${ }^{1}$, Hervé Devilliers ${ }^{1} .{ }^{1}$ University Hospital, internal medicine and systemic diseases, Dijon, France; ${ }^{2}$ University Hospital, ophthalmology, Dijon, France

Background: Dysthyroïd myopathy (DM) refers to Graves' ophthalmopathy (GO) in $90 \%$ of the cases but can also be observed with hypothyroidism, and is responsible for orbital fat and muscles inflammation. In those patients with euthyroidism and no thyroid receptor antibody, a strong argument for DM can be the aspect of the extra ocular muscles. In myositis of other causes, muscle insertions are increased in size. In DM, the insertions are respected and not increased in volume in magnetic resonance imaging. This was the case of our eight patients.

Objectives: To describe the efficacy of Tocilizumab (TCZ) in RDM in 8 patients

Methods: We conducted a monocenter study of 8 patients with RDM refractory to conventional treatment scheme

All patients have been treated following the EUGOGO (European Group on Graves' Orbitopathy) scheme, which consists in weekly infusions of $500 \mathrm{mg}$ prednisolone (4 to 6) followed by weekly infusions of $250 \mathrm{~g} \mathrm{(4}$ to 6). One patient had received before oral prednisolone, which is known to be less effective and no other immunosuppressive therapy.

The aim was to reduce the clinical activity score (CAS) of the disease to a score of 1 (score composed of 7 items)

Results: We studied 8 female patients (16 eyes); mean age at diagnosis $64,37 \pm 9,37$ years.

All patients had normal thyroid function at diagnosis. Three patients had a previous history of hashimoto's thyroiditis and the other 5 had no immunological abnormalities.

The duration of orbitopathy between first supposed manifestations and therapy onset was 5,7 months +/- 2,3. TCZ was introduced at the end of the steroid pulses, or before, during steroid therapy, in 2 patients who did not improve at all their ocular status after 3 steroid infusions. TCZ was used intravenously as a monotherapy, at the classical dosage of 8 $\mathrm{mg} / \mathrm{kg}$ per infusion, with no other immunosuppressives.

According to the classification of severity of the EUGOGO group using the CAS ${ }^{1}$, before TCZ, 1 had severe ( $n=2$ eyes) or moderate $(n=14$ eyes) disease. Moreover, patients presented exophthalmos ( $\mathrm{n}=16$ eyes), strabismus ( $\mathrm{n}=16$ eyes), muscle inflammation and volume increase at MRI and severe optic neuropathy $(n=1)$

After a mean of 4 pulses (extremes 1 to 7 ), all patients experienced improvement with TCZ withdrawal in all due to complete remission in 3 and regression in ocular inflammation in 5. Unfortunately, one patient relapsed two months after the 6th TCZ infusion, despite of initial complete remission and was treated with 4 weekly infusions of rituximab at $375 \mathrm{mg} / \mathrm{m} 2$ with a very good response three months later. Only one patient experienced a severe anal abcess after the first TCZ infusion leading to treatment interruption, but with a good improvement of DM. Improvement of ocular parameters with TCZ therapy. Data are expressed as mean $\pm S D$ or median [IQR]. (VA : visual acuity; IOP : intra ocular pressure; CAS : clinical activity score)

Before tocilizumab after tocilizumab

VA $0,7(0,3-1) 0,9(0,7-1)$

IOP $26,5+/-7,721,1+/-13$

CAS $4,25+/-1,281$

Conclusion: TCZ seems to be effective in RDM, as previously reported. In case of ineffectiveness or relapse, rituximab may be effective as well. This questions us about a new treatment scheme, which patients could benefit from biotherapies alone for a better and quicker efficiency?

\section{REFERENCES}

[1] - Dolman PJ. Grading Severity and Activity in Thyroid Eye Disease. Ophthalmic Plast Reconstr Surg. 2018;34(4S Suppl 1):S34-S40

Disclosure of Interests: Philip Bielefeld Consultant for: ABBVIE, Speakers bureau: ABBVIE, Florian Baudin: None declared, Julie Blanc: None declared, Alain Bron: None declared, Suzanne Mouries-Martin: None declared, Romain Bouvet: None declared, Hervé Devilliers: None declared DOI: 10.1136/annrheumdis-2019-eular.2847

\section{AB1081 A COMPARATIVE STUDY ON THE FEATURES OF THE SPINAL INVOLVEMENT IN SAPHO SYNDROME}

Xiaoli Deng ${ }^{1}$, Shuang Gao ${ }^{2}$, Lihua Zhang ${ }^{3}$, Le Song ${ }^{3} .{ }^{1}$ Peking University Third Hospital, Depatrment of Rheumatology and Immunology, Beijing, China; ${ }^{2}$ Peking University Third Hospital, Beijing, China; ${ }^{3}$ Peking Universtiy Third Hospital, Department of Radiology, Beijing, China

Background: SAPHO syndrome is a rare disease with the typical involvement of the anterior chest wall. The spinal involvement is more often than we thought and less understood by us.

Objectives: To assess the clinical and imaging features of the spinal involvement in SAPHO syndrome.

Methods: Patients diagnosed with SAPHO syndrome in Peking University Third Hospital from 2006 to 2018 were recruited. Patients were divided into spinal involvement group and non-spinal involvement group. Patients with AS (ankylosing spondylitis) were recruited as control group. Thei clinical data, laboratory data and imaging data (CT, MRI and radionuclide imaging) were collected and were conpared. All the patients with SAPHO syndrome were followed up regularly.

Results: Totally 46 SAPHO patients were included $(17$ male and 29 female) and 34 patients $(73.9 \%)$ had spinal involvement. The mean age was $50.2 \pm 10.9$ years and the mean disease duration was $5.4 \pm 6.4$ years. 50 patients with AS were also included.

Compared with non-spinal involvement group, the age at disease onset in spinal involvement group was older, the disease duration was longer,t he CRP elevation was more often and the anterior chest wall involvement was less often (table 1).

In spinal involvement group, the thoracic spine was most commonly involved and the vertebral inflammatory changes including bone marrow edema were often seen. These patients were more likely to suffer from cervical spine involvement, endplate inflammation and spondyldiscitis (table 2).

Abstract AB1081 Table 1. characteristics of SAPHO syndrome patients with and without spinal involvement

\begin{tabular}{lccc}
\hline characteristics & $\begin{array}{c}\text { Spinal involvement } \\
(\mathrm{n}=34)\end{array}$ & $\begin{array}{c}\text { Non-spinal involvement } \\
(\mathrm{n}=12)\end{array}$ & $\begin{array}{c}\mathrm{P} \\
\text { value }\end{array}$ \\
\hline Sex, female & $21(61.8 \%)$ & $8(36.7 \%)$ & $\mathrm{NS}$ \\
Age at diagnosis yrs & $52.2 \pm 10.3$ & $44.6 \pm 10.6$ & $0.033^{*}$ \\
Disease duration yrs & $6.1 \pm 7.1$ & $3.1 \pm 2.4$ & $0.048^{*}$ \\
Dermatological & $19(55.9 \%)$ & $10(83.3 \%)$ & $\mathrm{NS}$ \\
disorders & & & \\
CRP elevated & $21(4.6 \pm 12.1$ & $4(3.0 \pm 4.3$ & $0.047^{*}$ \\
ESR elevated & $16(31.2 \pm 24.0$ & $6(32.2 \pm 27.2$ & $\mathrm{NS}$ \\
TNF- $\alpha$ elevated & $12(58.6 \pm 55.9)$ & $13(45.3 \pm 22.7)$ & $\mathrm{NS}$ \\
IL-6 elevated & $18(320.5 \pm 343.9)$ & $42(48.6 \pm 328.2)$ & $\mathrm{NS}$ \\
sternoclavicular & 18 & 12 & $0.003^{*}$ \\
Clavicle & 6 & 2 & $\mathrm{NS}$ \\
First rib & 8 & 5 & $\mathrm{NS}$ \\
Sternocostal joint & 6 & 2 & $\mathrm{NS}$ \\
Sternum corner & 1 & 3 & $0.02^{*}$ \\
Manubrium & 6 & 0 & $\mathrm{NS}$ \\
Sacroiliac joint & 6 & 5 & $\mathrm{NS}$ \\
\hline
\end{tabular}


Abstract AB1081 Table 2. characteristics of SAPHO syndrome and AS patients with spinal involvement

\begin{tabular}{lccc}
\hline characteristics & $\begin{array}{c}\text { SAPHO } \\
(\mathrm{n}=34)\end{array}$ & AS $(\mathrm{n}=50)$ & $\mathrm{P}$ value \\
\hline Sex, female & $21(61.8 \%)$ & $17(34.0 \%)$ & $0.012^{*}$ \\
Age at onset, yrs & $52.2 \pm 10.3$ & $35.4 \pm 12.0$ & $0.0008^{*}$ \\
Disease duration, yrs & $6.1 \pm 7.1$ & $7.4 \pm 7.3$ & $\mathrm{NS}$ \\
CRP elevated & $16(4.6 \pm 12.1)$ & $26(2.11$ & $\mathrm{NS}$ \\
& & $\pm 2.52)$ & \\
ESR elevated & $16(31.2 \pm 24.0)$ & $18(28.4$ & $\mathrm{NS}$ \\
& & $\pm 24.6)$ & \\
HLA-B27 positive & $1(2.9 \%)$ & $48(96.0 \%)$ & $0.000^{*}$ \\
Cervical vertebra & $17(50.0 \%)$ & $13(26.0 \%)$ & $0.024^{*}$ \\
Thoracic vertebra & $22(64.7 \%)$ & $33(66.0 \%)$ & $\mathrm{NS}$ \\
Lumbar vertebra & $17(50 \%)$ & $34(68.0 \%)$ & $\mathrm{NS}$ \\
Contiguous/multiple vertebra & $28(82.4 \%)$ & $50(100 \%)$ & $0.002^{*}$ \\
involvement & & & \\
Vertebral inflammation & $34(100 \%)$ & $48(96.0 \%)$ & $\mathrm{NS}$ \\
Endplate inflammation & $8(23.5 \%)$ & $3(6.0 \%)$ & $0.019^{*}$ \\
Spondylodiscitis & $16(47.1 \%)$ & $4(8.0 \%)$ & $0.001^{*}$ \\
Vertebral body corner involvement & $11(32.4 \%)$ & $13(26.0 \%)$ & $\mathrm{NS}$ \\
Paravertebral ossification & $4(11.8 \%)$ & $5(10.0 \%)$ & $\mathrm{NS}$ \\
\hline
\end{tabular}

All the SAPHO patients with spinal involvement were followed up. 30 patients received NSAIDs plus DMARDS/biologics and the symptoms improved. Reexamined imaging data of 10 patients were available and the spinal involvement became better.

Conclusion: $73.9 \%$ of SAPHO patients had spinal involvement and they were more likely to suffer from cervical spine involvement, endplate inflammation and spondyldiscitis. The combination of NSAIDS and biologics/DMARDs were helpful to improve the symptoms.

\section{REFERENCES}

[1] Mcgauvran A M, Kotsenas A L, Diehn F E, et al. SAPHO Syndrome: Imaging Findings of Vertebral Involvement.[J]. Ajnr Am J Neuroradiol, 2016, 37 (8).

Acknowledgement: This study was supported by a Project of the National Natural Science Foundation of China (81501390).

Disclosure of Interests: None declared

DOI: 10.1136/annrheumdis-2019-eular.2736

\section{AB1082 IATROGENIC INFECTIOUS SPONDYLODISCITIS: 6 CASES}

rim dhahri, Maroua Slouma, Leila Metoui, Souha Hannachi, Imen Gharsallah, Bassem Louzir. Military Hospital of Tunis Tunisia, Internal Medicine, Tunis, Tunisia

Background: The increasing proportion of iatrogenic spondylodiscitis (SD) is a prominent feature of infectious DS in recent decades

Objectives: To describe iatrogenic clinical, aetiological and evolutive SD features.

Methods: We report 6 cases of iatrogenic DS collected in our department in 2001-2012 period.

Results: All patients were male. The average age was of 49 (35 to 68 years). Four cases of SD were caused by direct inoculation (surgical in 3 cases, chemonucleolysis in 1 case) and 2 cases of hematogenous SD from an initial outbreak. The seat of infection is lumbar in all cases. Spinal pain is almost constant. The admission examination noted apyrexia in 5 cases. A biological inflammatory syndrome was present in 5 cases and hyperleucocytosis in 2 cases. The bacteriological investigation was able to isolate a methicillin-sensitive Staphylococcus aureus (SAMS) and a proteus mirabilis in one patient and SAMS in another. The radiological assessment made it possible to objectify a para vertebral abscess in 5 cases and an epilepitis in 1 case. The evolution was favorable in all cases under antibiotherapy of average duration of 4.5 months and immobilization of the spine by corset.

Conclusion: The detection of an anaerobic germ causing infectious spondylodiscitis should search for an iatrogenic portal chronologically and anatomically close to the vertebral disc infection.

Disclosure of Interests: None declared

DOI: 10.1136/annrheumdis-2019-eular.8048
$\mathrm{AB} 1083$

IN A FAMILIAL MEDITERRANEAN FEVER PREVALENT REGION, ARE FAMILIAL MEDITERRANEAN FEVER AND BEHÇET'S DISEASE ASSOCIATED?

Ozgur Alparslan ${ }^{1}$, Bugra Han Egeli ${ }^{2}$, Yeltekin Demirel ${ }^{3}$, Serdal Ugurlu ${ }^{2}$.

${ }^{1}$ Gaziosmanpasa University, Tokat, Turkey, ${ }^{2}$ University of Istanbul-Cerrahpasa, Istanbul, Turkey, ${ }^{3}$ Sivas Cumhuriyet University, Sivas, Turkey

Background: The co-existence of Familial Mediterranean Fever (FMF) and Behçet's Disease (BD) has been questioned. There have been a variety of claims on a common pathogenesis.

Objectives: We intended to report the prevalence of Familial Mediterranean Fever (FMF) and Behçet's disease (BD) and comorbidity ratio of these two diseases in Sivas, Turkey, a city where FMF is known to be very high.

Methods: Seventy-two primary schools in the center of Sivas participated in the study. A total of 14881 randomized sample children from 6th, 7th, and 8th grades, and also 985 of them with their parents $(n: 978)$ were interviewed. During these interviews, the family tree up to second degree relatives was drawn. The presence of a diagnosis of FMF or BD was questioned. The ones who have a diagnosis were confirmed by contacting the medical centers. The ones who were suspected of a disease were further investigated at Sivas Cumhuriyet University Medical Faculty, Family Medicine Outpatient unit. For each disease a disease related history, physical examination, eye examination and pathergy test for $\mathrm{BD}$ were performed when needed.

Results: 985 students, 978 mothers, 953 fathers and 1876 relatives (4792 in total) were included in the study. Only $30(0.6 \%)$ of the sample was diagnosed with FMF, and $3(\% 0.06)$ was diagnosed with BD. One of them had concomitant FMF diagnosis.

Table. FMF symptoms within the last year

\begin{tabular}{lcc}
\hline Symptoms & N & $\%$ \\
\hline Abdominal Pain & 20 & 66.7 \\
Fever & 23 & 76.7 \\
Joint Pain & 8 & 26.7 \\
Chest Pain & 10 & 33.3 \\
Muscle Pain & 7 & 23.3 \\
Erysipelas like & 5 & 16.7 \\
erythema & & \\
\hline
\end{tabular}

Conclusion: The prevalence of FMF in Sivas is higher than Turkey's prevalence; however, BD prevalence was found very low. According to these findings, it is not easy to conclude that these two diseases share a similar background of pathogenesis.

Disclosure of Interests: None declared

DOI: 10.1136/annrheumdis-2019-eular.3896

\section{AB1084 PECULIARITIES OF ERYTHEMA NODOSUM ASSOCIATED WITH SARCOIDOSIS AND BACTERIAL- VIRAL INFECTION IN RHEUMATOLOGIST PRACTICE}

Olga Egorova, Boris Belov, Svetlana Glukhova. V.A. Nasonova Research Institute of Rheumatology, Moscow, Russian Federation

Background: Erythema nodosum (EN) is a nonspecific immune inflammatory syndrome, which is a septal panniculitis without vasculitis. Often EN acts as one of the symptoms of systemic pathology, which can cause late diagnosis and, accordingly, the appointment of adequate therapy. Objectives: to study clinical, laboratory and radiological data in EN in the acute form of sarcoidosis (SAR) and EN associated with bacterial and viral infection in patients sent to the rheumatology center.

Methods: The study included 312 patients $(61$ men and 251 women, age $35.4 \pm 8.2$ years) who applied to the clinic with a referral diagnosis of $\mathrm{EN}$ in 2007-2017. The median duration of the disease was $1.6[0.3 ; 4.7]$ months. All patients underwent a comprehensive clinical examination and laboratory and instrumental examination of biochemical, serological (ASL$\mathrm{O}$, antibodies against chlamydia and Mycoplasma of 2 classes, ureaplasmas, herpes viruses of type I and II, cytomegalovirus, Epstein-Barr virus hepatitis $\mathrm{B} / \mathrm{C}$, Yersinia, HIV, etc.) and immunological parameters, radiography or computed tomography (CT) of the chest organs. 